\title{
Mobile Payments in the United States at Retail Point of Sale: Current Market and Future Prospects
}

\author{
Marianne Crowe, Marc Rysman, and Joanna Stavins
}

\begin{abstract}
:
Although mobile payments are increasingly used in some countries, they have not been adopted widely in the United States so far, despite their potential to add value for consumers and streamline the payments system. After describing a few countries' experiences, we analyze the prospects for the U.S. market for mobile payments in retail payments, particularly the use of contactless and near-field communication technologies. We identify conditions that have facilitated some success in other countries and barriers to the adoption of mobile payments in the United States. On the demand side, consumers and merchants are well served by the current card system, and face a low expected benefit-cost ratio, at least in the short run. On the supply side, low market concentration and strong competitive forces of banks and mobile carriers make coordination of standards difficult. Furthermore, mobile payments are characterized by a network effects problem: consumers will not demand them until they know that enough merchants accept them, and merchants will not implement the technology until a critical mass of consumers justifies the cost of doing so. We present some policy recommendations that the Federal Reserve should consider.
\end{abstract}

\section{JEL Classifications: G21, L15, O33}

Marianne Crowe is a vice president and Joanna Stavins is a senior economist and policy advisor, both at the Federal Reserve Bank of Boston. Marc Rysman is an associate professor of economics at Boston University and a visiting scholar at the Federal Reserve Bank of Boston. Their e-mail addresses are marianne.crowe@bos.frb.org, joanna.stavins@bos.frb.org, and marc.rysman@bos.frb.org, respectively. We wish to thank Bruce Claflin, Darin Contini, Jeff Fuhrer, Fabia Gumbau-Brisa, Scott Schuh, Oz Shy, Jim Cunha, and Suzanne Lorant for helpful comments and suggestions. We also wish to thank the large number of people who talked with us, often at great length, about their perceptions of the industry, including members of the following organizations: AT\&T, the Federal Reserve Bank of Boston, the CTIA, the Federal Communication Commission, the Federal Trade Commission, the Financial Services Roundtable, the Mobey Forum, Venable LLC, and Verizon. The views expressed in this paper are solely those of the authors and do not reflect official positions of the Federal Reserve Bank of Boston or the Federal Reserve System.

This paper, which may be revised, is available on the web site of the Federal Reserve Bank of Boston at http://www.bos.frb.org/economic/ppdp/index.htm.

This version: May 17, 2010

\begin{tabular}{|l|l|l|l}
\hline $\mathrm{C}$ & $\mathrm{P}$ & CONSUMER PAYMENTS \\
\hline
\end{tabular} $\begin{array}{llll}\mathrm{R} & \mathrm{C} & \text { Research Center }\end{array}$ 


\section{Introduction}

The introduction of the mobile phone as a device for retail payments is an important frontier for both telecommunications and payments. The widespread use of mobile phones in the United States today signifies that a large portion of the public connects via these small computers that they carry. These devices can be outfitted with applications and new functionality that could improve the way that people conduct a variety of activities in their lives. One of the most interesting new possibilities is the ability to use a mobile phone as a payment device at a retail point of sale location.

We define mobile payments as the use of a mobile phone to make a payment at a physical retail location, whether or not the phone actually accesses the mobile network to make the payment. Definitions vary throughout the industry, but for the purpose of this paper, mobile payments do not include mobile banking transactions, which involve accessing bank services through a mobile device. ${ }^{1}$ Also, we are not primarily interested in mobile person-to-person (P2P) transfers, although to the extent that these systems can be adapted to retail transactions, they are mentioned in our discussion (Cheney 2008). ${ }^{2}$

Strong interest exists throughout the industry in the potential for mobile payments. The scope for bundling mobile payments with value-added services is great, and consumers are already conditioned to expect, and have shown a willingness to pay for, an ever-expanding array of innovative applications on their smart phones. The vision is exciting. Not only could a consumer simply wave a mobile phone in front of a reader and have his bank or payment card

\footnotetext{
${ }^{1}$ For example, one can often use the mobile banking bill-pay feature, which could be interpreted as a form of mobile payment but is actually more closely related to online banking, because with bill pay, a mobile phone is used to access one's bank account online.

${ }^{2}$ Mobile P2P (person to person) payments usually transfer money between parties that have a relationship (for example, family members or from a client to a service provider such as a babysitter, landscaper, or housekeeper, because this payment method requires the sender to know personal information (bank/account number, email address, phone number) about the receiver. There is usually an intermediary in the process (like PayPal, Obopay, or CashEdge). Mobile P2P transactions can and do occur today commercially in the United States, although not on a large scale.
} 
account debited automatically, but using the computing and communication power of a mobile phone, the customer could also perform many other activities at the same time. For instance, a consumer could compare prices with prices offered by other local merchants, store the payment record with his financial management software, download a warranty or instructional video on how to use a product, and more. Merchants could benefit by having the phones interact with reward or other promotional programs. And this technology could greatly increase the efficiency of the U.S. payment system by offering a payment method that would encourage the transition to electronic payments even for small dollar purchases. ${ }^{3}$

A number of countries have already integrated mobile phones into their payment systems, at least in some form. While substantial business and consumer interest exists in the United States, adoption has been slower here than in some other countries. What lessons can we learn from these countries? This paper examines the experience with mobile payments in Japan, Korea, and Spain, summarizes the status of mobile payments in the United States, and discusses prospects for future adoption. We review the technologies involved, discuss the adoption patterns and experiences in these countries, and draw lessons for the U.S. mobile payments business. Based on this analysis, we discuss U.S. prospects for adoption of mobile payments, raise issues concerning standards and oversight, and make policy recommendations for the Federal Reserve. Our analysis is based on the existing literature and on discussions with representatives of several mobile carriers, financial institutions, and payments industry consultancies. We present our conclusions and recommendations with the caveat that forecasting adoption of innovations is particularly difficult. The market is evolving rapidly with some developments hidden behind proprietary veils, so our understanding of current market conditions is necessarily only partial. Our analysis, conclusions, and recommendations should be read in this context and may change as we gain more knowledge.

\footnotetext{
${ }^{3}$ FirstData reports that 75 percent of consumers prefer cash over other payment methods for expenditures of $\$ 10$ or less, whereas only 10 percent of consumers prefer cash for expenditures over \$50. See McCarthy (2008).
} 
For technologies, we focus on contactless and near-field communication (NFC) technologies which, as we discuss in the paper, appear to be the most likely candidates to be adopted for retail payments, because of their convenience and sophistication. We identify supply-side and demand-side obstacles to the adoption of mobile payments and consider why the barriers have been difficult to overcome. We discuss the expected benefits from mobile payments for consumers and merchants, and their respective costs, and whether any market failures exist that would warrant policy intervention. On the supply side, we discuss issues of coordination, public goods, networks, and standards. In addition, we discuss the need to be proactive in ensuring that these emerging technologies improve or at least maintain, rather than impair, the security and robustness of the nation's payment system.

We do not find compelling evidence that mobile payments will experience widespread success in the United States in the near term (defined here as 1-3 years), although industry participants are continuing to experiment with pilots globally. Widespread deployment of NFC-enabled mobile phones, along with the requisite merchant readers, is costly, and the immediate benefits to each party appear to be small, given the widespread adoption and use of credit and debit cards in the United States. Over the next 3-5 years, as old mobile phones and merchant terminals require replacement, they may be replaced by phones and terminals that can process NFC contactless mobile payments, thereby removing some of the merchant barriers. Interestingly, Gauthier (2010) reaches conclusions similar to ours in a concurrent article.

In Section 2, we review the basic technologies that can be used to conduct mobile payments. Section 3 discusses the experience with mobile payments in Japan, South Korea, and Spain. Section 4 then draws lessons from these experiences and delves into obstacles to mobile payments in the United States. Section 5 discusses rationales and potential paths for public policy in this area, and Section 6 concludes. 


\section{Technology}

This section reviews the two basic methods by which a consumer could make retail purchases using a mobile phone as a payment instrument. The first is based on contactless and near-field communication (or NFC) technology. The second is based on text messaging, or short message service (SMS) ${ }^{4}$

\subsection{Contactless and Near-field Communication (NFC) Technology}

While the terms "NFC" and "contactless" are sometimes used interchangeably, they are slightly different. Formally, NFC technology allows two autonomously powered devices to communicate over short distances, typically less than six inches. For example, these devices might be a mobile telephone and a merchant reader. "Contactless" technology also allows for communication at short distances, although in this case, only one item may be powered. For example, a merchant reader may communicate with a contactless card, such as MasterCard PayPass and Visa PayWave. NFC devices use the "contactless" communication protocol. Thus, an NFC-enabled mobile phone can interact with a merchant reader designed to accept contactless cards. ${ }^{5}$ Many public transit systems, such as the Boston MBTA, use proprietary reloadable contactless cards to handle payments. Contactless technology can be embedded in several different devices, such as a plastic card, a key chain (or key "fob"), a cell phone cover, or a sticker that can be attached to any object, including a mobile phone. In contrast, the NFC chip and antenna are embedded in a mobile phone, where payment account information can be programmed, preloaded, or downloaded.

\footnotetext{
${ }^{4}$ While WAP (wireless application protocol)/Internet browser is a third platform that is used to access a website via a mobile phone and make a purchase, it is not included in this paper because it is not used for retail purchases at checkout counters.

${ }^{5}$ NFC and contactless are both defined by formal open standards that emerged from recognized industry standardsetting bodies. For example, NFC is defined by ECMA-340 (under the name NFCIP-1). See also publications from the NFC Forum. By "contactless," we refer to ISO/IEC 14443. Formally, NFC devices can do more than contactless devices since NFC devices by definition have their own power source. This difference does not appear to be important for payments at this point, as we envision mobile phones using their power source for applications such as searching the Web and displaying information to the screen, rather than special communication with the merchant reader beyond what a contactless card can do.
} 
Contactless technology has some important advantages over other payment methods, and embedding this technology in a mobile phone adds several more. First and foremost, using contactless technology for payments is fast, since the device holder can just wave a mobile wallet or other device in front of a reader. ${ }^{6}$ Contactless technology has the potential to move micropayments - typically defined as payments below \$10-into a digital form, particularly with Visa and MasterCard, eliminating signature requirements for settlement on such payments to interested merchants.

Another advantage of contactless technology is that the chip can be used to store much more information than can be stored on a magnetic strip, and the information can be updated by a reader or over the air. Applications might include storing information such as warranties, rewards programs, coupons, and stored value. Embedding this technology into a mobile phone makes it substantially more useful than other devices. Using the mobile phone as essentially a mini-computer, a consumer could store information for multiple payment accounts, view and manage stored information, incorporate expenditures into financial planning software, or search for a given product at nearby stores. The phone could also store personal information such as the holder's driver license, employment identification, and health records, read information from a poster, or interact with enabled surroundings in a variety of ways. In this sense, a mobile phone could become a "fully enabled digital wallet." 7

Evans and Schmalensee (2009) argue that new payment technologies are unlikely to succeed in the United States based only on the merits of increased speed or convenience, as these features are already well supplied by existing U.S. payment methods. Rather, they argue that the gains will come from what they call the "technological mash-up" of telephony and payments, and they speculate about a market for advertisements delivered to a mobile phone based on a

\footnotetext{
${ }^{6}$ After the reader receives the necessary data, the payment moves through the payment system as any other payment does. Typically, authentication, payment, and verification take a fraction of a second. A recent mobile contactless pilot in India showed that merchants viewed speed as the main advantage of contactless payments over credit cards (Edgar Dunn 2010).

7 A mobile wallet or "m-wallet" is a data repository on a mobile device that securely stores consumer information about a bank account, and/or payment instruments such as debit, credit, and prepaid cards, and enables the consumer to select from the payment methods stored to make payments and purchases from the mobile device.
} 
consumer's location and buying habits. They envision an advertising market similar to the flexible market for advertising created by search engines on the World Wide Web that target specific customer segments with presumably relevant ads, based on information gleaned from consumer profiling. This view implies that what may be needed to spark the broad adoption of mobile payments by consumers and merchants is a bundled offering that assembles a set of features appealing to a significant segment of the consumer market.

While contactless technology offers many advantages, it faces several hurdles: first of all, as with the introduction of any new technology, it requires investment. Merchants must purchase and install readers, typically at their own expense (estimated to be about $\$ 200$ per reader). ${ }^{8}$ Installing NFC technology on a mobile phone increases the incremental cost of manufacturing the phone (estimated at $\$ 10-\$ 15$ per phone). ${ }^{9}$ Another potential concern is security. In fact, NFC technology appears to raise very few new security concerns beyond those associated with traditional payment cards. ${ }^{10}$ While a hacker could steal data "out of the air," the data are generated in a way that makes them difficult to use in another transaction. Also, standard security concerns, such as the exposure of large digital warehouses of stored account numbers held by retailers, exist with both magnetic and NFC-enabled cards, and therefore NFC technology is no less secure than the technology used in other types of cards.

One issue worth noting is that using NFC for payments does not require the mobile phone to use the mobile network. A consumer may download account information over the mobile network to set up the functionality, but this can also be done by synchronizing a mobile phone

\footnotetext{
${ }^{8}$ Merchants that service high volumes of consumers in businesses where transaction speed is especially important have the most to gain from contactless technology. Commuter rail applications are natural examples. Stadiums provide another example where the benefits of speed in the form of faster moving lines could materially increase revenue. Contactless readers are more durable than magnetic stripe readers and do not need to be cleaned. Hence, Contactless technology can be implemented outdoors and in situations that lack a dedicated attendant, such as vending machines and parking meters. Speed may be less important in retail stores, but because convenience is important to consumers for all payments (Schuh and Stavins 2009), contactless can be useful in these venues as well. See www.1nbcard.com/content/contactless-payment-devices.html .

${ }^{9}$ See McCarthy (2008).

${ }^{10}$ For a discussion of security, see the proceedings of the conference "Pay on the Go: Consumers and Contactless Payment," organized by the Federal Trade Commission at the University of Washington in July 2008. http://www.ftc.gov/bcp/workshops/payonthego/index.shtml.
} 
with a computer. Once this process is completed, the consumer can use contactless functionality to pay for a purchase without accessing the mobile network. ${ }^{11}$ This feature may be beneficial, because contactless technology can work even where no mobile signal exists and when battery power is exhausted. These are important issues if people are to be convinced to rely on this technology as an alternative to carrying a wallet.

\subsection{Short message service (SMS)}

The second basic technology for mobile phone payments involves using the mobile network directly to transmit payment information to a bank or financial institution. Typically, this would be done with the SMS function (texting) or via a data connection. A user could type a message in the standard format, or, more commonly, by using an application that generates the message from information that he enters. Alternatively, the receiver can send a message to the sender, requesting payment, and the sender authorizes the payment by replying yes or no and possibly entering a password. Obopay and PayPal are leading examples of the use of SMS for mobile person-to-person (P2P) payments in the United States.

At this time, it is unclear how important SMS technology will become for retail payments. SMSbased systems require entering information into a mobile phone, a procedure that consumers may find inconvenient at the checkout counter. Furthermore, SMS requires a mobile signal and a charged battery, and so is less reliable. Obopay markets itself primarily as a service for payments that the consumer would otherwise have to make with cash. Such a service is useful in many P2P transactions, such as transferring money to a child at school or splitting a restaurant bill. ${ }^{12}$ P2P transfers can be large, but this technology is unlikely to be adopted widely for retail payments because of security limitations (lack of encryption) and a slower transaction process. In Section 3, we discuss an attempt to build a similar system in Spain. For the purpose of this paper we focus mainly on contactless and NFC implementation, as we expect it to be

\footnotetext{
${ }^{11}$ For this reason, some people exclude NFC technology on a phone from the definition of "mobile payments," restricting it to payments that use the mobile network. This paper defines mobile payments to include NFC. 12 See Shy (2010) for details on P2P payments.
} 
more important to retail mobile payments because SMS is less convenient and has security issues, although SMS and P2P may complement the mobile payments with alerts, balance checks, mobile marketing, and other functions.

We exclude several important areas from our discussion. For instance, e-commerce can be conducted from a mobile phone, a process sometimes referred to as m-commerce. That is, a consumer can use the web browser on a mobile device to visit a web site and make a purchase. Also, many consumers use their mobile phones to purchase digital content or software applications to use on their phones. Such purchases are usually charged directly to consumers' mobile phone accounts. We focus here on the use of an NFC-enabled mobile phone in retail transactions that involve the banking/payment system, including card networks.

\section{International Experience}

It is instructive to consider how mobile payments evolved in other countries, both those where the service has succeeded and those where it has not. We focus on three examples: Japan, South Korea, and Spain. We do not discuss in detail developing countries where mobile payments are used for person-to-person transactions among the unbanked, as those examples are less relevant for the United States, where the unbanked share of the population is relatively low.

\section{1. $\operatorname{Japan}^{13}$}

Sony developed a contactless technology called FeliCa in the late 1980s. The technology achieved high penetration in Japan when JR East, a major commuter railroad in Tokyo, implemented the technology in a reloadable, prepaid card format. Merchants could also adopt readers, so use of JR East cards expanded to making purchases, for instance at convenience stores near train stations. Railway commuters initially provided an essentially captive customer

\footnotetext{
${ }^{13}$ This section is based on Bradley, Eisenmann, Egawa, and Kanno (2006), Edelman and Hagiu (2009), and Bradford and Hayashi (2007).
} 
base and many were also customers of surrounding merchants, providing a favorable environment for mobile payments to spread to nearby merchants.

Sony and JR East developed the technology for mobile phones with NTT DoCoMo. DoCoMo, a spinoff from NTT that handled mobile telecommunications, was a natural choice, since it held a 50 percent market share in mobile services, far more than any competitor. After some small trials, DoCoMo introduced the technology nationally in 2004, selling mobile phones enabled with FeliCa and including an "e-wallet" application preloaded on each phone. Originally, consumers' prepaid accounts were associated with their phones. However, in late 2005, DoCoMo developed a system to allow consumer charges to go to their credit cards, and in 2006, DoCoMo itself entered the consumer credit business. In 2005, the other major mobile carriers implemented FeliCa and adopted mobile payments.

FeliCa provided DoCoMo with several revenue streams. However, we do not believe that any of those will be relevant in the U.S. market. Thus, U.S. carriers will most likely have to find alternative revenue sources if they adopt mobile payments. DoCoMo gained from FeliCa in several ways. First, and probably most importantly, DoCoMo became part-owner (along with Sony) of the company that licensed and managed FeliCa technology for other users, such as other mobile phone companies and merchants. Second, merchants paid a fee to receive e-money payments, typically 1 to 4 percent. Third, DoCoMo's early adoption and later innovations differentiated it from its competitors, possibly making it more costly for DoCoMo's mobile phone consumers to change carriers. Although the Japanese government had recently mandated phone number portability, a consumer was less likely to change brands if he had a substantial prepaid account with DoCoMo. Fourth, DoCoMo entered the credit business by purchasing a bank, eliminating the conflict that might otherwise exist between a mobile carrier and a bank (for example, over who "owns" the customer or which company receives the revenue). Finally, DoCoMo offered fee-based services, such as loyalty programs, to merchants.

Perhaps the fundamental explanation for Japan's higher adoption rate of mobile payments lies in the country's demographic, physical, and cultural characteristics. The country is 
predominantly urban and densely inhabited, has a population that is homogeneous and technically sophisticated but highly cash intensive, and relies heavily on mass transit. Over 70 percent of mobile phones in Japan have payment capability. Adoption of contactless cards by approximately 50 percent of Japan's population helped the transition to mobile payments (Ezell 2009). These characteristics and circumstances generate strong demand for fast and easy payments.

\subsection{South Korea ${ }^{14}$}

In 2002, two large telecoms launched competing payment systems in Korea. These were not successful, in part because they relied on less convenient infrared technology. Also, merchants needed separate readers to handle the different payment methods. A third telecom company, LG Telecom, partnered with Kookmin Bank to launch an NFC-based system in 2003. The system worked at public transit stations and ATM machines but not at retail merchants, and it allowed payments to be withdrawn only from accounts at Kookmin bank. This system proved to be a success, motivating the larger telecoms to introduce their own NFC systems by partnering with numerous banks. Visa and MasterCard introduced SIM card ${ }^{15}$ implementations in 2006, in which consumers inserted a special card into their mobile phones in order to make payments. However, if a consumer wanted to change payment applications, for instance to change to an account for train stations, he had to swap the SIM card in his device. Not until 2007 did mobile carriers start introducing devices that could hold and easily change between multiple payment cards. As in Japan, the high rate of progress with adoption of contactless cards in South Korea helped the transition to mobile payments.

\footnotetext{
14 This section is based on Bradford and Hayashi (2007) and Mas and Rotman (2008).

15 A SIM card, also known as a subscriber identity module, is a smart card that stores data for GSM (Global System for Mobile Communications) cellular telephone subscribers. Such data include user identity, location, and phone number, network authorization data, personal security keys, contact lists, and stored text messages. Security features include authentication and encryption to protect data and prevent eavesdropping. A SIM card can be switched easily from one phone to another.
} 


\subsection{Spain ${ }^{16}$}

Mobipay was formed in 2001, jointly owned by the major mobile carriers, financial institutions, and payment card companies. With Mobipay, a consumer can load multiple accounts onto his phone and make a purchase at a retailer either by giving his mobile phone number to the retailer or by having the phone display a special bar code that the merchant reads. The consumer then receives a message via SMS or data connection, confirming that he wants to make a payment. Also, to pay for something like parking, a consumer could "text" money to a parking meter with a digital address. Mobipay collects no fees for its services. It pays carriers for its use of the telecommunication networks from shareholder investments. Essentially, the shareholders are paying for a method to increase payment account and phone use.

Mobipay cannot be regarded as a success. By 2007, less than 1 percent of Spain's population had registered to use the service, and the actual use was presumably lower. Mas and Rotman (2008) argue that this lack of success stemmed from the fact that Mobipay did not generate any direct revenue and therefore could not fund any promotion. In contrast, the payment cards that competed with Mobipay were adopted widely and functioned well. In addition, no single firm could gain market share relative to its competitors from the success of the mobile technology, since it was a market-wide initiative. We argue below that these last two issues are particularly relevant when assessing the situation in the United States.

\section{Prospects for the United States}

Currently, it is impossible for a consumer to use a mobile phone to make a retail payment in the United States using NFC technology embedded in a phone, except as part of a trial sponsored by a mobile carrier or bank. ${ }^{17}$

\footnotetext{
16 This section is based on Mas and Rotman (2008).

17 NFC stickers or covers that can be placed on the outside of the mobile phone provide a peripheral bridge alternative. The stickers cost between $\$ 5$ and $\$ 10$ and require registration. Some are linked to general purpose credit cards, and others are prepaid, requiring reloads to add funds.
} 
Despite the high rate of mobile phone adoption in the United States, consumer demand for mobile payments is low, regardless of venue and whether via SMS text messages or contactless. The chart below shows supporting data from the FRB Boston 2008 and 2009 Survey of Consumer Payment Choice (SCPC).

Table 1: Mobile banking and mobile payments in the United States

\begin{tabular}{|c|l|l|}
\cline { 2 - 3 } \multicolumn{1}{l|}{} & 2009 & 2008 \\
\hline Bank account adopters & $93.0 \%$ & $93.8 \%$ \\
\hline Mobile banking adopters & & \\
\hline Used mobile banking in last 12 months & $8.9 \%$ & n.a. \\
\hline Cell phone adopters & $10.2 \%$ & \\
\hline Mobile payment adopters & $89.5 \%$ & n.a. \\
\hline Paid using SMS/Text & $3.0 \%$ & n.a. \\
\hline Paid via contactless mobile & $1.1 \%$ & \\
\hline
\end{tabular}

Source: 2008 and 2009 Survey of Consumer Payment Choice.

\subsection{Comparing the United States with other countries}

With regard to the prospects for retail mobile payments, the United States differs from Japanthe most successful of our examples-in several important respects.

Although closed transportation systems might be an ideal context for introducing contactless devices, the United States' large geographic size, dispersed population, and decentralized 
transit agencies make U.S. transportation systems less useful to serve as the gateway for widespread adoption of mobile payments. Yet there is a lesson that can be drawn from the Japanese case: having a captive or at least a loyal or otherwise "sticky" customer base of significant size is a great advantage for any entity that aims to introduce mobile payments. And the advantage is magnified if the possibility of natural dissemination (contagion) is also present.

A sophisticated and robust payment environment already exists in the United States and reliance on cash is lower than in many other countries, including Japan. Getting accurate measures of the use of cash is very difficult, but D'Silva (2009) computes the percentage of the dollar value of all consumer transactions that were paid in cash in 2006 across various countries. He finds that for Japan, South Korea, and Spain, the shares were 50, 34, and 26 percent, respectively. This ordering corresponds to the ranking of the success of mobile payment adoption in these countries. In the United States, the share of cash transactions is 14 percent. ${ }^{18}$ Because mobile payments typically replace low-value cash transactions, countries with a higher share of cash transactions have a larger potential market for mobile payments.

Figure 1 below shows the share of transactions at the retail checkout that are paid using cash, credit, and debit cards in a few developed countries. The share of cash transactions is lower in the United States than in any other country included here. Although we know of no comparable data for Japan, it is reasonable to expect that the share of cash there is at least as high as in any of the countries in Figure 1.

\footnotetext{
${ }^{18}$ One would expect all of these shares to be higher if we computed the percentage of the number of transactions rather than of the dollar value.
} 
Figure 1: Share of transactions at the checkout in selected countries (based on the number of transactions)

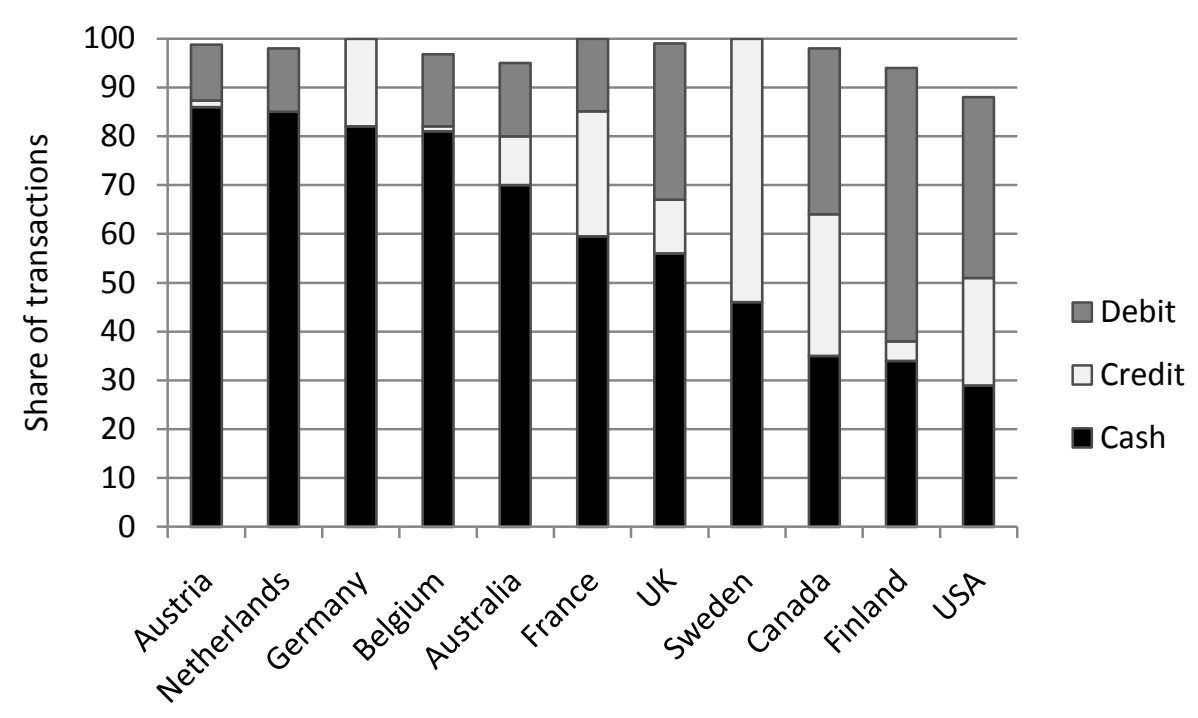

Source: Data source varies by country. Adapted from Eugenie Foster, LLC “What do we know about cash payments?" (Presented at the Central Bank Forum on Payment Surveys, Chicago, March 2009)

Mobile payments replace primarily cash transactions in Japan, while in the United States they would also compete with cash alternatives (checks, debit, credit, and prepaid cards). ${ }^{19}$ These electronic alternatives already offer many of the advantages of mobile payments, and they are widely accepted; therefore, the potential short-term benefits from adopting mobile payments in the United States are substantially lower than in Japan.

Japanese banks had a clear incentive to encourage the adoption of mobile payments, since they profit from bank-based payments, which mobile payments could expand significantly. In contrast, U.S. banks already profit from the payments that would be replaced. More

\footnotetext{
${ }^{19}$ In the United States, consumers' share of cash transactions in their payment portfolio is not high. According to the 2008 Survey of Consumer Payment Choice, in a typical month, 53 percent of consumer payments (retail and other) were made using cards and only 23 percent were made using cash.
} 
importantly, U.S. consumers typically prefer to use alternatives to cash for larger payments. ${ }^{20}$ Ignoring merchant fees, handling electronic payments is cheaper for merchants as well (GarciaSchwartz, Hahn, \& Layne-Farrar, 2006). Thus, mobile payments filled an important need in Japan, whereas in the United States they would be substituting for a system that is almost, if not equally, as good (at least in the near term, in terms of speed and convenience for consumers). Unlike the situation in Japan and South Korea, contactless cards have not been successful at generating demand for mobile payments in the United States. There are no reliable publicly available data on adoption of contactless cards in this country, and industry estimates vary widely. Regardless, consumer awareness remains low. Many cardholders receive contactless cards but are unaware that they have them or how to use them, and do not know whether merchants they frequent accept contactless payments.

Another important difference is that the United States has a much less concentrated market than Japan, both in banking and in mobile carriers. While DoCoMo has about 50 percent of the Japanese market in terms of the number of customers, each of the biggest U.S. carriers has less than 35 percent. The U.S. banking market is even less concentrated: the United States has almost 7,000 commercial banks, ${ }^{21}$ whereas when mobile payments were adopted in Japan, the country had 44 banks serving a population almost half the size of the U.S. population. ${ }^{22}$

Thus, low market concentration in banking and the existence of well-developed noncash payment systems form the background for understanding the barriers to adoption in the United States.

\footnotetext{
${ }^{20}$ Garcia-Schwartz, Hahn, and Layne-Farrar (2006) estimate that the average cash transaction is $\$ 11.52$, compared with $\$ 44.50$ for credit and $\$ 54$ for check. Rysman (2009a) reviews empirical studies of consumer payment choice in the United States. Note that we do not know of research on these issues that focuses specifically on Japan.

${ }^{21}$ According to the FDIC, there were 8,099 depository institutions in the United States as of September 30, $2009: 6,911$ commercial banks and 1,188 savings institutions.

${ }^{22}$ Even though the top banks hold the vast majority of deposits (the FDIC data show that the top four bank holding companies hold about 34 percent of all deposits), the mobile payment standards need to be interoperable across all banks for retail payments to be processed, just as the MICR line on paper checks is a common standard used by all U.S. banks. Thus, the number of banks is as relevant measure as the share of top institutions.
} 


\subsection{Barriers to adoption}

On the demand side, the expected near-term benefits of mobile payments to consumers are low relative to the cost, in the absence of new product offerings that could enhance the value proposition for consumers. The near-term benefit-cost ratio seems low for merchants as well.

On the supply side, we find four main barriers to achieving widespread adoption and use of mobile payments in the United States in the near term. One is the difficulty of coordinating all the parties that would have to be involved in order to develop industry-wide mobile payment standards. The Fed is naturally concerned with the adequacy of such standards as they impact the safety, robustness, and efficiency of the payments system. The difficulty inherent in coordinating many entities is exacerbated by the possibility that the significant players may want to position themselves to own the relationship with the customer and the rich set of information that mobile payment services could yield. ${ }^{23}$ As an aside, even preliminary jockeying for position over ownership of the customer relationship raises privacy and consumer protection issues that are of concern to the Fed. This brings us to the second supply-side barrier, the public good nature of any investment in standard development. While society as a whole would benefit from such standards, no single party has the appropriate incentive to invest in their development. The third supply-side barrier is the uncertainty created by the absence of a clear regulatory oversight authority and a lack of clarity about the rules and regulations that will govern mobile payments. This uncertainty inhibits potential market participants and intensifies the confusion over which entities have a chance at owning the customer relationship or how such ownership might be shared. The fourth major supply-side barrier is the lack of a viable business model that provides incentives to all relevant parties to invest in mobile payments technology and adopt the standards - the most challenging issue, according to our industry sources. This barrier encompasses both the supply side and the demand side and reflects the fact that thus far no venture has succeeded in developing and marketing a viable

\footnotetext{
${ }^{23}$ McCarthy (2008).
} 
offering that provides sufficient incentives to customers, merchants, and all who must be involved in the supply chain, while avoiding regulatory pitfalls.

\subsection{Demand-side barriers}

\subsubsection{Low benefits because of the existing payment system}

The United States has a well-established and widely adopted electronic payment system, with the majority of consumers carrying and using credit and debit cards. Cash-the payment method that mobile payments typically replace in other countries - is used much less frequently here than in the countries where mobile payments are significantly more successful (for example, Japan). Moreover, recent changes in the U.S. debit card regulation (Reg. E) eliminate the need for merchants to give receipts for small dollar purchases, thus speeding up debit transactions and reducing consumers' demand for faster payment method alternatives. ${ }^{24}$ Many merchants do not require signatures for low-value credit card transactions, either.

One advantage of contactless mobile payments over other payment instruments is speed. However, in a national survey, the Survey of Consumer Payment Choice, conducted for the Federal Reserve Bank of Boston in $2008,{ }^{25}$ only 4 percent of consumers indicated that speed is the most important attribute of payment instruments in general, while 18 percent indicated that speed is the least important feature. Moreover, cash was considered "very fast" by the majority of respondents. Although mobile payments were not included in that set of survey questions, replacing cash with a faster payment technology does not seem to be the most pressing need of consumers. Thus, increased speed does not appear to provide a strong incentive for consumers to adopt mobile payments.

\footnotetext{
${ }^{24}$ See Federal Reserve Board's Regulation E (Electronic Fund Transfers), 12 CFR §§ 205.9 and 205.11.
}

${ }^{25}$ Foster, et al. (2009). 


\subsubsection{High cost to consumers and merchants of upgrading to new technology}

Consumers would have to replace or upgrade their mobile phones with phones equipped with a designated NFC chip to be able to conduct mobile payments at physical retail locations. The additional cost of that technology has been estimated at $\$ 10-\$ 15$ per phone, and there would presumably be additional upfront investment by the handset manufacturers. ${ }^{26}$ The carriers and handset manufacturers are reluctant to invest in equipping the phones with the required chips until they receive more assurance that they will recoup the cost of doing so.

Perhaps a higher hurdle is that merchants would have to install contactless readers capable of processing mobile payments at each terminal/cash register. The additional cost of this technology has been estimated at $\$ 200$ per reader. Additional readers would not be required for merchants who have already installed readers to handle contactless cards, since NFC-enabled mobile phones can transact over the same readers. However, penetration of contactless readers has been low. ${ }^{27}$ While a few large merchants have adopted them, many appear hesitant to invest \$200 per reader until their existing readers need to be upgraded for other reasons. Besides the cost, the uncertainty about which standard will emerge as dominant appears to be deterring merchants from investing in this technology. For many merchants, the benefits are questionable. They can already accept payment cards using the magnetic stripe. The potential benefits of increased marketing opportunities, such as being able to store coupons or rewards programs on their customers' cards or mobile phones, are uncertain and require additional investment. And although accepting cash may be costly (armored trucks, safes, etc.), the fixed cost of cash processing will not be eliminated until all or most cash transactions have been replaced. Moreover-and more importantly-merchants would have to pay merchant fees for each contactless mobile payment, while no such fees are imposed on the cash transactions they

\footnotetext{
26 The Environmental Protection Agency estimates that consumers replace their mobile phones every 18 months (www.epa.gov), although according to industry sources, mobile phones are replaced every two years on average. If only a fraction of these consumers use NFC, the carrier has a limited amount of time in which to recover its cost.

${ }^{27}$ In the United States, 140,000 merchants have installed 500,000 contactless readers (Ezell 2009). According to the most recent U.S. Census (2007 data), this represents only 12 percent of the over 1.1 million total retail establishments in the country.
} 
would be replacing. It is unknown at this time whether mobile purchases charged to credit or debit accounts would incur additional merchant fees.

In addition to the explicit costs of technology adoption, the market exhibits a network effects problem because consumers' value from mobile payments depends on how many merchants accept them, and this in turn depends on how many consumers adopt them. Consumers are unlikely to pay the additional cost unless contactless mobile payments are widely accepted at retail locations - a problem that has existed in other payment technologies in the past. Similarly, merchants do not want to invest until it is clear that there will be widespread consumer adoption. This "chicken-and-egg" problem can be difficult to overcome, particularly for mobile payments, where there are multiple parties in the "chicken and egg" problem (mobile carriers, banks, handset manufacturers, chipmakers, merchants, and consumers), making the resolution much more complex.

As discussed above, installing NFC chips on mobile handsets involves a variable cost, and developing the handset involves a substantial fixed cost. Naturally, the smaller a prospective market for a given handset, the more of the development cost must be recouped per handset and thus the higher the average cost of a handset. One potential "bridge" alternative is to install contactless technology on an SD (secure digital memory) card that can be inserted into a handset so it can be accessed by the handset's operating system. ${ }^{28}$ Consumers could buy the SD cards or the cards could be distributed by a merchant or transit authority with preloaded account information. This approach may provide a short-term solution to overcome the need to develop specialized handsets until mobile payments become more popular and the market can bear the cost of building NFC technology into the handsets. ${ }^{29}$

28 For instance, see http://www.paymentsnews.com/2009/11/devicefidelity-introduces-in2pay-microsd-based-nfcsolution.html, accessed on November 13, 2009.

${ }^{29}$ In February 2010, VISA and DeviceFidelity announced plans to launch a contactless-enabled microSD memory card for mobile phones. The mobile device will work at any designated payWave location. Trials are due to begin in Q2 2010, although it is not likely any trials will occur in the United States. See Datamonitor (2010). 


\subsection{Supply-side barriers}

\subsubsection{Need for coordination}

The U.S. banking and mobile carrier industries have very low market concentration compared with other developed or developing countries. Because there are many banks and four major mobile carriers, industry-wide agreements on technology standards and business policies are very difficult to coordinate and negotiate to reach consensus. Bilateral negotiations between a single bank and a single carrier are much easier, but the market share of customers having accounts with both the bank and the carrier for any given pair of institutions is likely to be small, lowering the value of any resulting agreement. In addition to the decentralized horizontal structure described above, vertical coordination is made difficult because of the number of parties involved in each transaction: a mobile carrier, a handset manufacturer, a card association (for example, VISA, MasterCard), a mobile software vendor, a bank, a merchant, and a consumer. The parties would have to agree on who is responsible for verifying the consumer's identity, for resolving disputes, handling customer service, etc. A bank might be concerned about potential damage to its reputation in case a payment is not executed because of an issue involving a carrier. Carriers have never been involved in financial services and would have to tackle a host of new legal and regulatory issues.

Table 2: $\quad$ Coordination or Standardization Game (Battle of the Sexes)

Firm 2

\begin{tabular}{|c|c|c|c|c|c|}
\hline \multirow{3}{*}{ Firm 1} & \multirow[b]{2}{*}{ Standard $\alpha$} & \multicolumn{2}{|c|}{ Standard $\alpha$} & \multicolumn{2}{|c|}{ Standard $\beta$} \\
\hline & & 200 & 100 & 0 & 0 \\
\hline & Standard $\beta$ & 0 & 0 & 100 & 200 \\
\hline
\end{tabular}

Source: Adapted from Shy (2001). 
Table 2 demonstrates the standardization problem faced by the players in this market, using a coordination game commonly called the Battle of the Sexes. In this example, there are two firms (Firm 1 and Firm 2), and two standards ( $\alpha$ and $\beta$ ). Both firms are better off if they choose the same standard, but because Firm 1 stands to gain more from standard $\alpha$ and Firm 2 stands to gain more from standard $\beta$, they may end up selecting different standards if they do not coordinate. Coordination enables the firms to select the same standard and makes all the players better off. In the case of mobile payments, coordination among the large number of firms involved is necessary in order to help them agree on a single industry standard.

\subsubsection{Public good nature of industry standards}

Industry standards for mobile payments would specify the technical details and process for exchanging data between mobile devices, financial institutions, and merchants. A common industry standard would allow any firms that adopted the standards to participate. Looking at examples of similar hi-tech industries, all have used standards. Some use open, negotiated standards (for example, DVDs, cell phones, web browsers), while others use proprietary standards (VCRs, some computer operating systems). But because participants expect that an industry standard will eventually be publicly available (as we explain below), any private party investing in the development of the mobile payments standard would help other potential adopters. The private benefits accrued by each party would be much smaller than the private costs that would have to be expended.

Why are industry-wide standards necessary? Without industry standards in place, none of the potential alternative scenarios would ever satisfy all of the stakeholders. For example, in one alternative to industry-wide standards, mobile carriers could offer the payment service without direct bank involvement. A mobile carrier could settle payments through the customer's monthly mobile phone bill - this is how consumers currently purchase mobile applications and digital content. However, there are substantial costs and risks to expanding this service to retail payments at the checkout counter. The scale would be much larger, and the carrier would have to work with merchants to ensure acceptance, perhaps involving the installation of new 
contactless readers, which is particularly challenging if a carrier has only a fraction of the market and consumers can change carriers at a relatively low cost. In addition, carriers would be de facto entering the business of banking. This means they would need to evaluate the creditworthiness of customers, verify their identity, charge interest, collect from customers who revolve debt, provide customer service, guarantee payment and settlement to merchants, and provide timely customer notifications and disclosures that address consumer liabilities, responsibilities, and recourse. It would also necessitate complying with a large number of complex banking regulations. Consumer willingness to enter into new payment relationships presents another challenge, especially with a nonbank, and one much less familiar with the payment process (unlike, for example, PayPal with 10 years of payments experience).

Another approach would require consumers to prepay their mobile phone accounts and would restrict consumers to pay only from those funds. This is the strategy that DoCoMo originally followed. However, such an approach avoids only some obstacles and significantly limits consumer use and convenience, particularly for consumers who already have debit, credit, or prepaid cards. For unbanked or financially constrained consumers, this option might be attractive.

Another alternative to industry-wide standards would be a bilateral contract between a carrier and a bank or card company to allow the two agreeing firms to participate but exclude others, limiting customer access and choice and hindering interoperability. Banks are likely to resist entering a bilateral agreement that associates them with a single mobile carrier. If a bank's customers change carriers or are dissatisfied with the carrier's service, a complex issue of customer service and allocation of responsibility between the bank and the carrier must be resolved. The problems with the carrier's service might damage the bank's reputation in the minds of the bank's consumers. As in scenario one, the market share of consumers who use both the bank and the carrier is likely to be low, and convincing a manufacturer to develop a handset for a market with a relatively small maximum size is a challenge. 
Thus, the development of open industry-wide standards through collaboration of industry stakeholders may be the most likely path towards successful adoption of mobile payments. Standards can be of two types, open or proprietary. ${ }^{30}$ An open standard is developed by a standard-setting committee, in which any interested party may participate. Such committees typically require a consensus vote. While committee members may hold patents on a standard, the standard-setting organization usually requires the members to commit to reasonable and nondiscriminatory pricing. ${ }^{31}$ These groups have no enforcement power-it behooves them to generate standards that their constituencies will accept. ${ }^{32}$

It is an open question whether a proprietary standard, like FeliCa in Japan, or an open standard will ultimately be successful in this industry. It is possible that proprietary standards, perhaps on SD cards as mentioned above, will be the first successful applications but that the market will ultimately turn towards an open standard. Importantly, an open standard for mobile payments is under development currently. The financial industry standard-setting group ASC X9 has a working group developing U.S. standards, and ISO has a working group developing an international version of the standards. ISO and X9 are voluntary standard-setting organizations. ${ }^{33}$ The $\mathrm{X} 9$ and ISO standards will specify how a mobile phone formats information about a bank account and delivers that information to a merchant's card reader via NFC technology. The standards also address many issues related to security, such as PIN requirements and the carrier's ability to shut down the payment features of a phone remotely in case of a loss or theft. Any bank, mobile carrier, or other vendor that develops its service in compliance with the standards would be able to participate in the mobile payments market. Once the standards are designed, each company that adopts them would have to pay to make

\footnotetext{
${ }^{30}$ Greenstein and Rysman (2007) discuss this issue in the context of computer modems.

31 The exact meaning of "reasonable prices" is hotly debated. Furthermore, there may still be non-participants that hold patents over the technology, and they will have to be addressed at some point. For a discussion of these issues and others involving intellectual property and standard setting, see Lemley (2002) and Kobayahsi \& Wright (2009).

32 A proprietary standard is developed by one or a group of firms, explicitly owned or licensed by them.

33 ASC X9 (Accredited Standards Committee X9) is an industry nonprofit association composed of members of the financial services industry. ISO (International Organization for Standardization) is a network of national standards institutes of 162 countries, one member per country. It is the world's largest developer and publisher of international standards.
} 
software or hardware changes to incorporate the standards into their own systems. Cost recovery for any of these companies would vary and be uncertain. Standard-setting processes can be slowed significantly when there is strong commercial interest in the outcome (see Simcoe (2008) and Farrell \& Simcoe (2009)). At this stage, prospects for the ultimate development of mobile payment standards appear to be strong, although their readiness is at least 18 months away.

However, developing a standard does not ensure that it will be adopted. A great deal of literature on voluntary standard-setting considers the factors that predict when a codified open standard is actually adopted and implemented. For instance, see Egyedi \& Dahanayake (2003) and Farrell \& Saloner (1998). While the people we spoke with stated that an industry standard was necessary for adoption, it appeared that their individual knowledge of the standard-setting efforts at X9 and ISO was surprisingly low.

Because open standards are already being developed by groups representing multiple stakeholders, both in the United States and internationally, there is no need right now for the Federal Reserve or any other government body to step in to coordinate the standards beyond our existing membership and active participation in the standards development on X9 and ISO.

\subsubsection{The Business Model}

Among the people with whom we spoke, the lack of an appropriate business model was cited as the biggest obstacle preventing widespread adoption of mobile payments. The business model specifies the value proposition and expected revenue sources for all parties, the roles of the various participants, and how the parties will compensate one another for their activity.

We consider possible value propositions and associated revenue sources from the perspective of the offering as a whole, looking first at consumers.

Consumers appear to be highly resistant to paying for handsets, except possibly for smart phones with significant value-added capabilities. Also, consumer demand appears to be highly 
elastic with respect to explicit costs associated with payments, as illustrated by payment card resistance to credit card surcharging in Europe and Australia. ${ }^{34}$ Consumers may have little incentive to pay for the basic mobile payment service when they can use their magnetic stripe card or enable their card or key chain with contactless functionality. However, consumers might be willing to pay for a broader set of mobile payment services. Among the complementary services that might be offered would be merchant loyalty programs in which consumers receive alerts telling them how close they are to earning rewards. Another type of complementary service would be access to applications that integrate payments with financial management software. As is generally the case with any product that has not yet been brought to market, the willingness of consumers to pay for these services is unclear. Further research might help us estimate consumers' willingness to pay for the additional services of a mobile wallet that contains cards and links to bank accounts, and has the ability to send and receive text alerts, as well as other capabilities and services.

The incentive to differentiate was very important in encouraging adoption in Japan and Korea. This may also be true in the United States on the front end. On the other hand, the incentive to differentiate on the back end appears to be absent in the United States, where an interoperable industry standard serving all carriers appears to be the only viable, or at least the overwhelmingly superior, alternative for mobile payments. Assuming that an industry standard for mobile payments is required in the United States for a venture to have first-mover advantage, it must be able to offer mobile payments with additional value added capabilities. Mas and Rotman (2008) speculate that the industry-wide nature of Mobipay in Spain hurt adoption by eliminating the possibility of reaping rewards from a first-mover advantage with a differentiated offering.

\footnotetext{
${ }^{34}$ Although the practice is controversial, payment card companies such as Visa and MasterCard require merchants to follow a "no-surcharging" rule in the United States. That is, merchants offering Visa and MasterCard may not charge consumers explicitly to use credit cards rather than another payment method. However, surcharging exists in some countries, and it strongly impacts consumers' payment decisions (Bolt, Jonker, \& van Renselaar, in press).
} 
A second potential source of revenue is merchants. Merchant resistance to interchange and other fees is well known. Given that merchants would have to bear the fixed cost of installing readers, it seems unlikely that they would also be willing to pay the marginal cost of each transaction, considering the lack of demonstrated demand and therefore the uncertain prospects for cost recovery. However, merchants might value and be willing to pay for the ability to incorporate promotions and customer loyalty programs into the mobile payments process, with products that included valuable new features.

Banks are another potential source of revenue. If NFC-enabled phones are simply going to replace payments that would have been made with other bank-issued payment instruments, banks' incentive to pay for mobile payments is severely limited. ${ }^{35}$ To the extent that mobile payments might replace cash, banks would be incented to generate new transaction revenues to reduce the costs of handling cash. From the point of view of banks and the payments system as a whole, the greatest incremental value of NFC technology appears to be in micropayments, for which cash is still preferred over cards (although debit cards have already replaced cash for low-value transactions to some extent). In addition, merchants, banks, and consumers may benefit from consumers' carrying their payment information on mobile phones that can flexibly handle new tasks and provide consumers with immediate access to information about their credit and bank account balances to help them manage their spending. Additional benefit could stem from a well-designed NFC-enabled phone that can actually increase security over the current mix of cash, card, and electronic payments through multiple levels of authentication, alerts, and other real-time information. Given the importance of security in the current payments market, banks and consumers might value these features. A further reason for banks to participate is to preempt the possibility of other payments arrangements that might bypass the banks and perhaps replace some debit and credit card transactions.

\footnotetext{
35 In Europe and many other countries, interchange fees are much lower than in the United States, in part for regulatory and antitrust reasons. See Bradford and Hayashi (2008). Hence, the prospect for direct payment from banks to carriers abroad seems even more limited.
} 
Carriers might also have an incentive to encourage mobile payments, in that increased use of their networks could result in increased revenues. We should note that carriers have the ability to proceed with implementation of mobile payments without banks. This occurred in Japan, where DoCoMo introduced mobile payments with a prepaid system that did not include banks directly. While there are barriers to unilateral development by carriers, card issuance has been lucrative for U.S. banks, so mobile carriers might consider this option if there is little movement towards a more collaborative approach in the near future.

Carriers could generate revenues from end customers, since they currently charge consumers for use of the network, as well as from merchants and/or banks, including charges for advertising. Carriers and other participants in the supply chain could pay or receive a percentage of the value of each transaction, a fixed amount for each transaction, or perhaps a fee for/from each consumer who installs bank account information on his mobile phone or participates in an mobile payments service. The various participants would have to negotiate the levels of these prices, based on their contribution, role, and bargaining power.

Why is it so difficult to construct an appropriate business model that all necessary participants can embrace? We view this problem as a symptom of the other issues we have discussed. The short-run benefits appear small if the focus is on basic mobile payments alone, not because of any technical limitations, but because the existing payment alternatives are efficient and effective. Hence, in the absence of complementary product offerings, the interested parties are bargaining over what they may see as a relatively small near-term surplus, and the difficulty of bargaining is magnified because many stakeholders are involved. Furthermore, there is considerable uncertainty concerning the kinds of services that consumers and/or merchants might value. The long-run benefits to society of having an effective mobile wallet technology may be large, but they are uncertain and may be difficult to appropriate by the firms that must make the largest investments.

Despite the barriers, there are reasons to be hopeful about the prospects for the development and implementation of a successful business model. Although the current well-developed 
payments system in the United States limits incentives for participants on both the supply side and the demand side to adopt a costly new technology, the possibility of including complementary services that go well beyond mobile payments suggests that there may be hope for a successful mobile payments business for the United States.

\subsubsection{Lack of clear regulatory oversight and regulations}

Providing mobile payments involves entities in several different industries currently supervised by different agencies: financial institutions are regulated by the Federal Deposit Insurance Corporation (FDIC), the Office of the Comptroller of the Currency (OCC), the Federal Reserve, the Office of Thrift Supervision (OTS), and the National Credit Union Administration (NCUA); mobile carriers are regulated by the Federal Communications Commission (FCC); the Federal Trade Commission oversees competition more generally. The use of a mobile device to make payments and purchases falls outside the regulatory boundaries defined by each agency. For example, FCC regulation does not address mobile payments or financial transactions specifically for carriers. Financial regulators do not currently distinguish between risks stemming from payments initiated via a mobile phone and those stemming from any other payment method. To ensure the safety, robustness, and stability of the U.S. payments system broadly defined, these regulatory bodies need to be better aligned to close the gaps in order for mobile payments to be considered a viable payment option.

Regulatory oversight would have to be provided by one or more government agencies experienced in regulating financial transactions in order to manage risk and security, including consumer protection, for mobile payment transactions. The existing boundaries would most likely have to be extended to include not only mobile payments for purchases at retail locations, but also mobile payments over the Internet, and/or via mobile P2P payments. Many private sector stakeholders cited two major obstacles to their participation: (1) lack of clarity as to who will regulate mobile payments and how these payments will be regulated and (2) lack of guidance on which current regulations cover mobile payments. 


\section{Policy Recommendations}

At this stage, the rationale for any public policy intervention to promote mobile payments is unclear. Indeed, the major reason for the lack of progress in the United States is the limited prospect for realizing sufficient social net benefits from this product in the short run, rather than market failure. If the technology creates benefits that cannot be captured by pricing plans for mobile phones or payments, we cannot expect private industry to lead the way towards adoption, even if it were clear that adoption would be socially beneficial. Since we cannot reliably estimate the overall social benefits at this time, we do not recommend government intervention involving any type of financial subsidy. However, the complexity and importance of the safety, robustness, and integrity of the payments system do suggest a degree of ongoing involvement by the Federal Reserve. We offer several steps the Federal Reserve should take to ensure that the mobile technology and the industry stay in sync with the regulatory framework. Such efforts might have the side effect of supporting the adoption of mobile payments

\subsection{Conduct quantitative research, including survey and market research, to estimate the potential value of mobile payments in the United States.}

We will not be able to quantify the potential benefits or indeed the prospect for mobile payments on the demand side until we understand what consumers value. The private sector has conducted consumer-side research, surveys and opinion focus groups, as well as pilots, but their research is proprietary and is likely to be biased, and there is no publicly available objective research. There are potential social welfare gains from mobile payments on the consumer side. Compared with the existing retail payments alternatives, consumers might benefit from greater convenience, increased security of mobile payments (via the option to receive balance and transaction alerts), reduced time spent in line, time saved from not having to go to an ATM, access to information on warranty and product reviews, the ability to compare prices across merchants and/or apply electronic coupons, and other possible capabilities. But because mobile payments have not yet been commercially implemented in the United States, surveying consumers on their preferences is the best way to evaluate those potential benefits. 
Research on consumer demand could help us assess consumers' willingness to pay for replacing low-value cash (and possibly some check, credit, and debit card) transactions with mobile payments, using a mobile wallet. Consumer and merchant research could also help to identify potential new areas that are vulnerable to fraud and any need for additional consumer protection.

Mobile payments could reduce the social cost of payment processing if they replaced more costly alternatives, such as cash or checks. For example, low-value mobile payments might reduce the use of coins and currency, particularly if the use of mobile payments with the public transit agencies expanded. However, we lack adequate information to determine whether mobile payments are truly more efficient than other payments. As one step, the Survey of Consumer Payments Choice conducted by the Federal Reserve Bank of Boston could be expanded to add a diary that better tracks small transactions, to estimate the potential benefits from replacing coins and currency with contactless and other forms of mobile payments. If operational cost savings to the Fed and/or the financial sector are estimated to be relatively high, this may be another reason for the Federal Reserve to help remove some of the marketrelated obstacles mentioned above.

\subsection{Help to establish regulatory guidelines for security and privacy and to clarify oversight responsibilities}

Although preserving the stability of the payments system is within the Fed's mandate, there is ambiguity regarding which agency or agencies would be responsible for regulating mobile payments. According to our industry sources, this ambiguity, including which guidelines apply, is one of the barriers to private sector innovation in mobile payments. Currently, mobile payments could fall under several jurisdictions. ${ }^{36}$ It is not obvious who would be responsible for security and consumer protection for mobile payments. The FCC traditionally has not been

\footnotetext{
36 The Federal Trade Commission (FTC) has a general mandate to address consumer protection and privacy, the Federal Reserve (FRB) supervises commercial banking, the OCC supervises large banks, and the FCC supervises mobile phone carriers and mobile communication. Each agency employs a different set of regulations to accomplish a separate set of objectives.
} 
primarily concerned with consumer protection or disclosure, but instead with ensuring that communication networks work in a technical sense and that communication markets are competitive and not concentrated. In contrast, the Federal Reserve considers consumer protection with regards to financial issues, but lacks direct jurisdiction over mobile payments. An example of a confusing regulatory issue is the oversight of Obopay. A consumer can access Obopay either through a bank website or through an application on his mobile phone. The service is covered by banking regulations in the first case, but not in the second, although the service is exactly the same. In the second case, the consumer is protected only by the terms and conditions established by the service provider.

The Federal Reserve could address this issue by convening a group of regulatory agencies to start planning potential regulatory changes in advance of the widespread adoption of mobile payments and by raising the issue with legislators and the administration. For instance, a Radio Frequency Identification (RFID) Intra-Government Council already exists, consisting of members of several agencies, including the FCC, the FTC, the Department of Defense and the National Institute for Standards and Technology (NIST). ${ }^{37}$ Perhaps a similar council could handle policy issues for mobile payments or at least publicly establish the boundaries of agency oversight.

Resolution of this issue may help to set the context for determining which type of entity plays the lead in assembling the various pieces of the first successful offering and in determining the business model, but the reverse may also be true: whether the first successful offering is led by a carrier, a bank, a technology vendor, or another type of entity may also influence the identity of the appropriate regulator.

${ }^{37}$ http://docs.google.com/gview?a=v\&q=cache:yRBPQf8vt90J:csrc.nist.gov/groups/SMA/ispab/documents/minutes/200 5-06/Junrcne2005-RFID-Handout.pdf+intra-+government+RFID\&hl=en\&gl=us 


\subsection{Facilitate coordination of industry-wide standards that ensure the continued safety, soundness and efficiency of the payments system by establishing a neutral setting where all the stakeholders can exchange ideas without concerns about collusion.}

There is a need for technical and process standards concerning the interface with the rest of the payments system. This is an area where the Federal Reserve has the opportunity to reduce a key area of uncertainty. The Fed could facilitate coordination of industry-wide open standards and business rules by establishing a neutral setting where all the stakeholders can exchange ideas and negotiate resolution of common requirements. The Federal Reserve is not the only possible agency that could do this, but there are compelling reasons for the Fed to get involved. As the central bank and a payment service provider, the Federal Reserve has a key responsibility for ensuring the integrity, effectiveness, and accessibility of U.S. payment systems. Because mobile purchases can be made via the $\mathrm{ACH}$ network, the Fed as the primary $\mathrm{ACH}$ operator has an additional responsibility to be involved. While mobile payments are just starting to emerge as a payment method, ${ }^{38}$ the Fed needs to understand this market segment better and, specifically, to understand the challenges resulting from involving several parties from multiple nonbank sectors. The Fed's involvement would ensure that the process has credibility and integrity. The Federal Reserve Bank of Boston participates in the NACHA Internet Council Mobile Payments Workgroup and in both the international (ISO) and U.S. (ASC X.9) standards committees, which are working to develop open technical standards for formatting mobile payment transactions. Facilitating such a process would continue a long tradition of the Fed's involvement in standards setting. ${ }^{39}$

The timing of broad mobile payment implementation is uncertain, but bringing the interested parties together is a relatively low-cost initiative to begin to remove the barriers. In January and April 2010, the Fed hosted meetings with key mobile industry stakeholders to better understand

\footnotetext{
38 The use of mobile payments for donations to Haiti (albeit through the use of text messaging, not contactless technology) showed that mobile payments are technically possible.

${ }^{39}$ In the past, the Fed was instrumental in organizing a standards work group to develop check image technology, proposed a check endorsement standard that helped to implement the Expedited Funds Availability Act, and worked with banks to implement the MICR line standard. See Connolly and Eisenmenger (2000) for a historical perspective and Oliver and Weiner (2009) for current initiatives.
} 
perspectives, roles, and responsibilities of the various parties involved in U.S. mobile payments. ${ }^{40}$ At these meetings, stakeholders discussed barriers and possible solutions to mobile payment growth in the United States, as well as areas where discussion among the parties involved could be helpful without running afoul of antitrust issues. In February 2010, the Board of Governors' Division of Consumer and Community Affairs hosted another mobile industry event $-\mathrm{a}$ forum on consumer protection and education issues associated with mobile financial services. It is important for the Fed to monitor the development of mobile payments to forestall any excessive increase in risk to consumers or to the payment system as a whole and to foresee any issues that might require regulation in the future. The Fed is also interested in the industry's views on what role the Federal Reserve should be playing to promote innovation, efficiency, and security in mobile payment systems. The Federal Reserve's involvement early on would ensure that the standards that emerge as a result of the negotiations are consistent with consumer protection goals.

These recommendations do not eliminate the industry's need to arrive at a viable business model. Industry-wide discussion of the business model among potential or actual competitors has the potential to raise charges of collusion. One policy that the government could consider is to exempt a particular set of discussions from charges of collusion, treating such discussions similarly to the way research joint ventures (RJVs) are treated. ${ }^{41}$ The Antitrust Division of the Department of Justice (DOJ) and the FTC have authority to declare that they view a particular agreement as legal under the antitrust law (although doing so does not guarantee that a court will find an action legal in a litigated case). As an example, the DOJ and the FTC recently

\footnotetext{
${ }^{40}$ The meetings were hosted jointly by the Boston and Atlanta Feds. Invited organizations included financial institutions, mobile network operators/carriers, card networks, payments processors, handset manufacturers, relevant trade groups, and key mobile payment platform and application vendors.

41 See Grossman and Shapiro (1986).
} 
switched to encouraging standard-setting organizations to engage in simultaneous discussion of technical standards and licensing prices. ${ }^{42}$

\section{Conclusion}

What are the prospects for mobile payments in the United States? We do not expect mobile payments to be successful on a wide scale in the near future, that is, in at least the next 1-3 years, for a variety of reasons. The United States currently has a very well-developed and efficient payment system, and enabling mobile payments via contactless technology would require a major investment in contactless chips and readers. Thus, the ratio of benefits to costs is extremely low in the short run. Even if the social net benefits were positive, private net benefits for each party might be negative. Furthermore, the lack of concentration in the telecommunication and financial services markets means that it is difficult both for one firm to lead the market and for groups of firms to negotiate a successful joint agreement. In addition, and perhaps most importantly, industry participants appear to be far apart right now on their ideas of what an industry-wide agreement should look like. Although it appears that some useful standards, both proprietary and open, will be available in the short or medium term, they will not be widely adopted until a business model develops that gives industry participants incentives to support this product, or until consumer demand for mobile payment services increases substantially.

Despite some serious obstacles, the potential long-run benefits of the mobile phone serving as a "fully-enabled digital wallet" are large, from the storage of payment accounts, health records, and identification to the "technological mash-up" of payments, telecommunication, and advertising envisioned by Evans and Schmalensee (2009). We certainly expect to see some progress on U.S. mobile payments in the near future, although on a limited scale. It is possible that a public transit system will develop a chip to enable a mobile device to serve as the

\footnotetext{
42 Another example is the use of patent pools, in which groups of independent patent owners market their licenses jointly, providing technology users with "one-stop shopping" to implement a particular technology and theoretically alleviating the inefficiency associated with independent pricing of complementary goods.
} 
payment device, perhaps with one or more regional carriers. Such a project could be successful with a proprietary standard rather than an open one, allowing the party making the initial investment to accrue the benefits. The public transit industry may have the best opportunity to lay the groundwork for more widespread adoption of mobile payments because of their obvious benefits in a cash-intensive, time-sensitive, high-volume market with a captive ridership, along with the contactless technology already implemented on proprietary transit cards in many areas of the United States today. Based on the successes with contactless card technology for the migration of payments for transportation to mobile phones in Hong Kong, Japan, and the United Kingdom, the U.S. transit system might be a good model to examine further.

In summary, we recommend three general policy initiatives for the Federal Reserve:

- Conduct survey research to learn about the benefits of mobile payments to consumers and businesses, and thus estimate potential social welfare gains.

- Promote and participate in establishment of appropriate regulatory oversight for mobile payments.

- Facilitate coordination among private industry stakeholders to help them establish common industry standards. 


\section{References}

Bolt, W., Jonker, N., \& van Renselaar, C. (in press). Incentives at the Counter: An Empirical Analysis of Surcharging Card Payments and Payment Behaviour in the Netherlands. Journal of Banking and Finance .

Bradford, T., \& Hayashi, F. (2007). Complex Landscapes: Mobile Payments in Japan, South Korea and the United States. Federal Reserve Bank of Kansas City.

Bradford, T., \& Hayashi, F. (2008). Deveopments in Interchange Fees in the United States and Abroad. Kansas City Federal Reserve Bank Payment Systems Research Briefing .

Bradley, S. P., Eisenmann, T., Egawa, M., \& Kanno, A. (2006). NTT DoCoMo, Inc.: Mobile FeliCa. Cambridge: Harvard Business School Case 9-805-124.

Claessens, S., \& Laeven, L. (2004). What Drives Bank Competition? Some International Evidence. Journal of Money, Credit and Banking , 36, 563-583.

Cheney, J. S. (2008). An Examination of Mobile Banking and Mobile Payments: Building Adoption as Experience Goods? Federal Reserve bank of Philadelphia Discussion Paper (June).

Datamonitor (2010). Visa and DeviceFidelity to offer new mobile contactless payments solution. February, http://www.datamonitor.com/store/Browse/?Ntt=DeviceFidelity\&N=359+354.

D'Silva, V. (2009). Payments in Flux: Megatrends Reshape the Industry. In R. E. Litan, \& M. N. Bailey, Moving Money: The Future of Consumer Payments (pp. 19-35). Washington, DC: Brookings Institution Press.

Egyedi, T. M., \& Dahanayake, A. (2003). Difficulties Implementing Standards. SIIT 2003 Proceedings (pp. 75-84). Piscataway, NJ: IEEE.

Evans, D. S., \& Schmalensee, R. (2009). Innovation and Evolution of the Payments Industry. In R. E. Litan, \& M. N. Baily, Moving Money: The Future of Consumer Payments (pp. 36-76). Washington, D.C.: Brookings Institution Press.

Ezell, S. J. (2009). Information Technology \& Innovation Foundation Report (ITIF), November.

Farrell, J., \& Saloner, G. (1998). Coordination through Committees and Markets. RAND Journal of Economics , 235-252. 
Farrell, J., \& Simcoe, T. (2009). Choosing the Rules for Consensus Standardization. Unpublished Manuscript, Boston University School of Management.

Federal Reserve Board's Regulation E. http://ecfr.gpoaccess.gov/cgi/t/text/textidx?c=ecfr\&sid=635f26c4af3e2fe4327fd25ef4cb5638\&tpl=/ecfrbrowse/Title12/12cfr205_m ain_02.tpl

Federal Trade Commission (2008). Pay on the Go: Consumers and Contactless Payment, conference at the University of Washington, July. http://www.ftc.gov/bcp/workshops/payonthego/index.shtml.

Foster, K., E. Meijer, S. Schuh, and M. A. Zabek (2009). The 2008 Survey of Consumer Payment Choice. Federal Reserve Bank of Boston Public Policy Discussion Paper No. 09-10.

Garcia-Schwartz, D. D., Hahn, R. W., \& Layne-Farrar, A. (2006). The Move Towards a Cashless Society: A Closer Look at Payment Industry Economics. The Review of Network Economics , 5, 175-198.

Gauthier, P. (2010, February 16). NFC: Past, Present, and Future. PYMNTS.COM .

Greenstein, S., \& Rysman, M. (2007). Coordination Costs and Standard SettingL Lessons from 56K Modems. In S. Greenstein, \& V. Stango, Standards and Public Policy (pp. 123159). Cambridge: Cambridge University Press.

Heyt-Benjamin, Bailey, D. V., Fu, K., Juels, A., \& O'Hare, T. (2007). Vulnerabilities in First-Generation RFID-enabled Credit Cards. Proceedings of Eleventh International Conference on Financial Cryptography and Data Security. Lowlands, Scarborough, Trinidad/Tobago.

Japan, C. P. (2009). Edelman, Benjamin; Hagiu, Andrei. Cambridge: Harvard Business School Case 909-007.

Kobayahsi, B. H., \& Wright, J. D. (2009). Intellectual Property and Standard Setting. George Mason University Law and Economics Research Paper Series 09-40.

Lemley, M. A. (2002). Intellectual Property Rights and Standard Setting Organizations. California Law Review , 90.

Mas, I., \& Rotman, S. (2008). Going Cashless at the Point of Sale: Hits and Misses in the Developed Countries. Washington, D.C.: Focus Note 51, CGAP. 
McCarthy, B. (2008). Mobile Payments: The Linchpin of the Mobile Commerce Economy. White Paper, First Data.

Rysman, M. (2009a). Consumer Payment Choice: Measurement Issues. Unpublished Manuscript, Boston University.

Shy, O. (2010). Person-to-Person Electronic Funds Transfers: Recent Developments and Policy Issues. Federal Reserve Bank of Boston Public Policy Discussion Paper 10-1.

Simcoe, T. (2008). Standard-Setting Committees. Unpublished Manuscript, Boston University School of Management.

The Mobey Forum. (2008). Best Practices for Financial Services: Business Enrolment Model Analysis.

U.S. Department of Justice and the Federal Trade Commission. (2007). Antitrust Enforcement and Intellectual Property Rights: Promoting Innovation and Competition. 